\title{
A liberdade educa ou a educação liberta? Uma crítica das pedagogias da autonomia à luz do pensamento de Hannah Arendt
}

José Sérgio Carvalho

Universidade de São Paulo

\section{Resumo}

A vinculação entre os objetivos do processo educacional e os ideais de liberdade e autonomia parece ser um elemento comum e recorrente nos mais variados discursos pedagógicos que marcaram o século XX. À primeira vista esse aparente consenso poderia indicar um raro acordo em um campo marcado por disputas teóricas e práticas, em geral fundadas em pressupostos divergentes e que costumam apontar para ideais conflituosos e procedimentos alternativos. No presente artigo, procura-se argumentar no sentido de que essa aparente unanimidade tende a se esvair na medida em que se elucidam os diferentes sentidos atribuídos ao ideal de "liberdade" e que se confrontam os esforços práticos por meio dos quais se busca realizá-lo no campo da educação. Para isso, recorrese à análise de algumas das diferentes acepções do conceito de "liberdade", opondo a concepção que nela vê um desígnio político a ser alcançado na vida pública às correntes que a identificam ora com a faculdade subjetiva da vontade, ora com a não interferência na escolha individual. Por último, procura-se vincular algumas dessas concepções de liberdade a diferentes discursos pedagógicos, analisando-se a voga das correntes vinculadas à "pedagogia da autonomia" à luz do pensamento político de Hannah Arendt e de suas reflexões sobre a crise da educação no mundo moderno.

\section{Palavras-chave}

Filosofia da Educação - Educação e liberdade - Teorias da educação - Arendt. 


\title{
Does freedom educate, or does education free? A critique of the pedagogies of autonomy in the light of Hannah Arendt's thinking
}

José Sérgio Carvalho

Universidade de São Paulo

\begin{abstract}
The link between the objectives of the educational process and the ideals of freedom and autonomy seems to be a common and recurrent element throughout the various pedagogical discourses that left their mark on the 20th century. At first sight, this apparent consensus could indicate a rare agreement within a field characterized by theoretical and practical disputes, usually grounded on diverging assumptions, and that tend to point to conflicting ideals and alternative procedures. In this article, we try to argue that such apparent unanimity tends to vanish as we unveil the different meanings attributed to the ideal of "freedom", and compare the practical efforts through which such ideal is pursued within the field of education. For that, we make use of the analyses of different senses of the concept of "freedom", contrasting the conception that sees in it a political goal to be achieved in public life with the currents that identify it either with the subjective faculty of the will, or with the non-interference in individual choices. Lastly, we seek to establish the connection between these conceptions of freedom and different pedagogical discourses, analyzing the current trends associated with the "pedagogy of autonomy" in the light of the political thinking of Hannah Arendt and her reflections about the education crisis of the modern world.
\end{abstract}

\section{Keywords}

Philosophy of Education - Education and freedom - Theories of education - Arendt.

\footnotetext{
Contact:

José Sérgio F. de Carvalho

Rua Gaicá, 108

05579-070 - São Paulo - SP

E-mail: jsfcusp@usp.br
} 
[...] Liberdade, essa palavra que o sonho humano alimenta, que não há ninguém que explique e ninguém que não entenda... (Cecília Meireles)

Há alguns anos, uma revista mensal de política e cultura me sugeriu como objeto de reflexão o dilema: a liberdade educa ou a educação liberta $?^{1} \mathrm{Na}$ ocasião, senti-me premido pelo espaço e tempo concedidos, mas desafiado pela ideia de examinar um fenômeno intrigante e paradoxal. Trata-se do fato de que, ao longo do século XX, pensadores radicalmente diferentes em termos de interesses e perspectivas teóricas pareciam ter um ponto de convergência: vinculavam de forma substancial o sentido da ação educativa ao cultivo de um compromisso para com a "liberdade". Seria a análise do dilema proposto um caminho interessante para deslindar divergências e confrontar tendências entre o aparente - ou verbalmente - consensual?

Retomo, então, o dilema, menos na expectativa de apresentar uma resposta direta do que para, a partir dele, formular algumas das bases sobre as quais repousam o consenso aparente e o dissenso latente em diferentes visões sobre as relações entre ação educativa e liberdade. Convém ressaltar, desde logo, que seu equacionamento exige a formulação de novas perguntas: a que noção de liberdade ele se refere? À corrente entre os antigos, concebida como um status político, na qual o "homem livre" é aquele dotado dos direitos da cidadania? $\mathrm{Ou}$ à concebida pelos modernos, inicialmente centrada no direito dos indivíduos às liberdades civis (de opinião, de credo religioso etc.) e progressivamente estendida para outras esferas, nas quais o indivíduo livre é concebido como aquele capaz de fazer escolhas próprias a partir de seu livre-arbítrio e de sua consciência? Ou ainda a liberdade como vivência escolar, tal como sugerem os discursos das chamadas pedagogias "não diretivas" em suas críticas às "escolas tradicionais"? E ainda, com que noções de educação e práticas educativas estamos lidando?

Essas breves considerações já indicam um dos problemas fundamentais desse tipo de discussão: "liberdade" - aliás, assim como "educação" - é um termo polissêmico eivado de sacralidade e impregnado por paixões teóricas e políticas, o que o torna objeto de inevitáveis disputas conceituais. No entanto, os discursos educacionais sobre as conexões entre formação escolar e "liberdade" raramente se preocupam em elucidar, dentro de um quadro relativamente claro de ideias ou perspectivas, os sentidos atribuídos aos termos em questão e às disputas teóricas e programáticas que ensejam. Não se trata de cair na tentação do que Passmore (1984) chamou de "falácia socrática": a crença de que uma discussão proveitosa sobre um tema exige definições prévias e exaustivas de seus conceitos fundamentais. Trata-se simplesmente de reconhecer que a enunciação de um compromisso com "a liberdade" - ou a denúncia acerca de sua ausência - tem sido proclamada como se os objetos em questão fossem evidentes e livres de ambiguidades, como se as disputas não envolvessem os próprios conceitos em torno dos quais se organiza a controvérsia.

É importante, contudo, ressaltar que não se trata de uma ambiguidade essencial do termo "liberdade", mas de uma variedade de possíveis significações e conceitos alternativos em seu uso corrente nos discursos políticos e educacionais. Assim, se um prisioneiro diz que "almeja a liberdade", o termo tem um sentido claro e dá pouca margem a interpretações ambíguas; tratase de se livrar da restrição imposta pelo cárcere, por exemplo. No entanto, em discursos políticos, o recurso ao termo "liberdade" pode ligar-se a concepções e acepções bastante distintas entre si, por vezes mesmo conflitantes ou alternativas. Não seria sequer estranho que um discurso de exortação à busca da "liberdade" pudesse almejar a "liberdade" de consciência religiosa ou a "liberdade" de iniciativa econômica; a "liberdade" como liberação das condições de vida materialmente opressoras ou como a possibilidade de livre escolha do consumidor. No campo dos discursos educacionais, a variabilidade, em

1. Trata-se da publicação Caros Amigos. 
geral irreconciliável, de acepções e concepções não é menor. E as diferenças não são simples aspectos variados de um mesmo núcleo essencial. Espelham, antes, disputas e controvérsias teóricas e práticas, e constituem o que Scheffler (1968) denomina de definições programáticas, já que sua enunciação e veiculação não têm caráter exclusiva ou preponderantemente elucidativo, mas também - e sobretudo - propósitos persuasivos.

Ao se recorrer a uma definição programática - ou conceituação persuasiva -, o que se almeja não é a mera elucidação do modo corrente de utilização de um conceito, a exemplo de quando explicamos a alguém o uso do termo "vírus". 0 que se busca é propor uma acepção que, mesmo não violentando abertamente seu uso corrente, sugira um significado fundamental impregnado de valores, em geral comprometido com a transformação ou com a justificação de práticas sociais, daí seu caráter programático ou persuasivo.

Pense-se, por exemplo, na disputa, marcante ao longo da segunda metade do século XX, envolvendo o conceito de "democracia". Por um lado, buscava-se associá-la de forma imediata e essencial ao liberalismo político e ao pluripartidarismo; por outro, à igualdade de acesso a direitos sociais e à elevação das condições de vida da classe trabalhadora. A luta entre concepções alternativas não tinha como alvo somente uma elucidação teórica, mas almejava precisamente justificar ou transformar práticas sociais a partir da veiculação ou do uso de um conceito, que ganhava, assim, um caráter programático ou persuasivo.

A veiculação, no âmbito dos discursos educacionais, do ideal de uma "formação para a cidadania" parece ser, hoje, um dos casos mais emblemáticos dessa luta pela aceitação e legitimidade de um dentre vários conceitos alternativos que têm não só um interesse teórico, mas um propósito prático. Sob uma mesma fórmula verbal - a educação para a cidadania - é possível identificar desde a veiculação de propostas de doutrinação para a conformidade legal até a proposição de uma radical crítica social, de projetos ecológicos à caridade ou ao trabalho voluntário.

Por essa razão, muitas vezes a aparente unanimidade na aceitação retórica de um ideal ou objetivo educacional - como este sobre o qual refletimos - pode esconder profundas divergências que só virão à tona caso se explicitem as concepções e práticas alternativas que as perspectivas teóricas e os programas de ação em disputa identificam como formas de realização histórica do ideal proclamado. Em texto publicado na década de oitenta, Azanha (1987), ao analisar a adesão unânime ao ideal de “democratização do ensino”, ressalta:

[...] é a unanimidade na superfície e a divergência profunda acerca do significado de "democracia" que torna muito difícil o esclarecimento da noção derivada de "ensino democrático" [pois] não é a profissão de fé democrática que divide os educadores brasileiros [... mas] é nos esforços de realização histórica desse ideal que as raízes das posições e das divergências se revelam. (p. 26)

0 mesmo se passa com expressões que parecem gozar de uma aparente unanimidade no plano da retórica educacional contemporânea. Pensemos, a título de ilustração, nas questões implicadas no uso da expressão "educação de qualidade” (Carvalho, 2004). Também neste caso se trata de uma reivindicação aparentemente unânime, pela qual os mais diversos segmentos sociais no Brasil se têm manifestado há décadas. Mesmo ignorando a variação histórica e se atendo a alguns agentes e instituições sociais contemporâneos, é pouco provável que, por exemplo, a Fiesp e a CUT, o Estado e a família, os professores e os responsáveis por políticas públicas tenham, todos, as mesmas expectativas quanto ao que poderia ser uma "educação de qualidade”. Algo análogo poderia ser dito sobre o que nos leva a adjetivar a ação educativa como detentora de "qualidade", ou seja, com que práticas e resultados identificamos sua presença em uma e não em outra instituição. 
Para uns, a "educação de qualidade" deve resultar na aquisição de diferentes informações e "competências" que capacitarão os alunos a se tornarem trabalhadores diligentes; para outros, líderes sindicais contestadores, cidadãos solidários ou empreendedores de êxito, pessoas letradas ou consumidores conscientes. Ora, é evidente que, embora algumas dessas expectativas sejam compatíveis entre si, outras são alternativas ou conflitantes, pois a prioridade dada a um aspecto pode dificultar ou inviabilizar outro. Uma escola que tenha como objetivo maior - e, portanto, como critério máximo de qualidade a aprovação no vestibular pode buscar a criação de classes homogêneas e alunos competitivos, o que dificulta a oportunidade de convivência com a diferença e reduz a possibilidade de se cultivar o espírito de solidariedade. Assim, as "competências" que definiriam a "qualidade" em uma proposta educacional significariam um fracasso - ou ausência de qualidade - em outra.

Por outro lado, para certas correntes de pensamento, a própria ideia de que uma escola de "qualidade" deva se ater ao desenvolvimento de "competências" ou "capacidades" pode comprometer o ideal educativo, já que os termos "competência" e "capacidade" não revelam, em seu uso comum, um necessário compromisso ético para além da eficácia. Platão, por exemplo, argumenta nesse sentido, em seu diálogo Górgias: um orador "competente" pode usar sua capacidade tanto para persuadir uma comunidade a aceitar uma "lei justa" como uma "lei injusta”. A competência se mede, portanto, pela eficácia dos resultados. Mas o mesmo não vale para o cultivo de um princípio ético. Pode-se dizer que alguém é um "orador competente", mas usa sua competência para o "mal"; embora não tenha sentido afirmar que alguém é "justo" para o mal, pois seria injusto. Assim, a ação educativa de "qualidade" é, para Platão, essencialmente de natureza política e ética, e não apenas eficaz no desenvolvimento de "competências" ou "capacidades".

Embora sumária, essa análise ilustra o tipo de dificuldade e a variedade de perspectivas que se apresentam quando o foco de nossas reflexões se volta para uma ação educativa que tenha como ideal o cultivo de princípios éticos e políticos, como é o caso da noção de "liberdade".

\section{O caráter programático do conceito de liberdade: $\mathrm{H}$. Arendt e B. Constant}

Tomemos, novamente, a título de exemplo, a pergunta: Sócrates era um homem livre? Um grego que lhe fosse contemporâneo responderia afırmativamente, sem hesitar. Era um cidadão ateniense, com direito a voz e voto nas assembleias, podia participar da vida pública, exercia na Praça Pública - na Agora - e nos Ginásios sua liberdade, como seus concidadãos. Era livre porque cidadão de uma polis livre.

Ao comentar essa concepção de liberdade, concebida como uma potencialidade da vida política, Arendt (1978) afirma que, para os antigos:

Antes que se tornasse um atributo do pensamento ou uma qualidade da vontade, a liberdade era entendida como o estado do homem livre, que o capacitava a se mover, a se afastar de casa, a sair para o mundo e a se encontrar com outras pessoas em palavras e ações. Essa liberdade, é claro, era precedida da liberação: para ser livre, o homem deve ter se liberado das necessidades da vida. 0 estado de liberdade, porém não se seguia automaticamente ao ato de liberação. A liberdade necessitava, além da mera liberação, $d a$ companhia de outros homens que estivessem no mesmo estado, e também de um espaço público comum para encontrá-los - um mundo politicamente organizado, em outras palavras, no qual cada homem livre poderia inserir-se por palavras e feitos. (p. 194, grifos nossos)

Claro está que Arendt, ao recorrer à experiência política das poleis democráticas para elucidar o sentido da noção de "liberdade" como atributo da vida pública, não está interessada 
exclusiva ou preponderantemente na apresentação de um dado histórico. Trata-se de, por meio da análise de um momento histórico, ressaltar uma dimensão do conceito de liberdade que foi obliterada a partir da emergência das noções estoica e cristã de "liberdade interior". Em ambas, em que pesem outras importantes diferenças, concebe-se a "liberdade" como faculdade de escolha de um indivíduo, por exemplo, em face de uma contingência da vida ou de um dilema ético. A liberdade migra, assim, do âmbito da ação política na esfera pública para o do interior da alma humana. Sua experiência deixa de ser ligada ao poder de homens que agem em concerto, para se referir a uma característica do tipo de relação que se estabelece entre um indivíduo e sua consciência ou sua vontade.

Assim, ao desvelar o processo de interiorização da liberdade, Arendt (1995) reafirma sua preocupação com a dignidade da ação politica, na medida em que esta potencializa a liberdade como faculdade humana de fazer emergir algo inesperado, romper com processos históricos automáticos cristalizados numa ordem política e social herdada para criar o novo, para começar algo imprevisto e imprevisível:

Fluindo na direção da morte, a vida do homem arrastaria consigo, inevitavelmente, todas as coisas humanas para a ruína e a destruição, se não fosse a faculdade humana de interrompêlas e iniciar algo novo, faculdade inerente à ação como perene advertência de que os homens, embora devam morrer, não nascem para morrer, mas para começar. (p. 258)

Assim, ontologicamente radicada no homem como faculdade, a liberdade se manifesta como fenômeno tangível e público na ação que, ao romper com o passado, cria o novo, dá à luz algo que não se reduz a uma consequência “necessária” desse passado, nem à atualização de uma potencialidade previamente vislumbrada, mas que, como um milagre, interrompe um processo automático de forma inesperada. Há, pois, um inegável sentido programático na distinção por ela proposta entre "liberdade" como condição política e como autonomia da consciência ou da vontade; ainda que tal distinção não vise uma orientação prática imediata de qualquer sorte ${ }^{2}$.

E não é menos potencialmente programática ou persuasiva a clássica concepção da liberdade dos modernos, tal como a propõe Benjamin Constant (1985) ao contrastá-la com a dos antigos:

0 que em nossos dias um inglês, um francês, um habitante dos Estados Unidos da América entendem pela palavra liberdade? [...] É para cada um o direito de não se submeter senão às leis, de não poder ser preso, nem detido, nem condenado, nem maltratado de nenhuma maneira, pelo efeito da vontade arbitrária de um ou de vários indivíduos. É para cada um o direito de dizer sua opinião, de escolher seu trabalho e de exercê-lo; de dispor de sua propriedade, até de abusar dela; de ir e vir, sem necessitar de permissão e sem ter que prestar conta de seus motivos ou de seus passos. É para cada um o direito de reunir-se a outros indivíduos, seja para discutir sobre seus interesses, seja para professar o culto que ele e seus associados preferirem, seja simplesmente para preencher seus dias e suas horas de maneira mais condizente com suas inclinações, com suas fantasias. (p. 81, grifos meus)

Ora, é evidente que, em face dessa formulação do conceito de liberdade, a resposta à pergunta anterior - "Sócrates era um homem livre?" - seria necessariamente outra. Poderia ser objetado que, apesar de cidadão de uma polis, Sócrates não tinha o direito de exercitar livremente sua crítica, já que ela o levou à condenação e à morte, num claro constrangimento à liberdade de consciência, escolha e expressão individual. Ao contrário da noção anterior, na

2. Deve-se destacar que o caráter programático ou persuasivo de uma definição ou conceito depende não de sua formulação, mas do contexto linguístico em que ocorre. Assim, uma mesma formulação linguística pode ter ora um papel programático, ora descritivo ou elucidativo. 
qual a realização da liberdade exige a $a c ̧ a ̃ o$ política e, portanto, o encontro entre pares num espaço comum que comporte a pluralidade dos homens, a concepção apresentada por Constant é a da liberdade do indivíduo. Nela a liberdade identifica-se antes com a garantia de limites de interferência nas escolhas individuais do que com o poder de ação conjunta. Trata-se de uma liberdade em relação ao outro, enquanto a dos antigos é concebida como a capacidade de ruptura em relação ao passado, decorrente da autonomia política dos cidadãos. Por isso, muitas vezes a concepção moderna que identifica a liberdade com os direitos civis tem sido definida como uma "liberdade negativa", no sentido de que se realiza por meio das garantias de "não interferência" do Estado em âmbitos fundamentais da vida de um indivíduo. Como destaca Berlin (2002):

[...] a defesa da liberdade consiste na meta negativa de evitar a interferência [...]. Essa é a liberdade como foi concebida pelos liberais no mundo moderno desde Erasmo aos nossos. Toda reivindicação de liberdades civis e direitos individuais, todo protesto contra a exploração e a humilhação, contra o abuso da autoridade pública, ou a hipnose de massa do costume ou da propaganda organizada, nasce dessa concepção individualista e muito controvertida acerca do homem. (p. 262, grifos nossos)

É importante frisar que não se trata da mera substituição histórica de um conceito por outro, tido por mais adequado, como no caso do conceito de "movimento" na física moderna em relação à aristotélica. Tampouco de duas concepções que, por incidirem sobre aspectos diferentes da experiência de liberdade, podem ser somadas e harmonizadas sem grandes conflitos. Embora não sejam logicamente incompatíveis, essas concepções de liberdade - como atributo da vida política ou como conjunto de liberdades individuais e direitos civis - representam, historicamente, perspectivas alternativas engendradas por modos de vida distintos e alimentadas por princípios muitas vezes conflitantes.
É evidente que a dicotomia apresentada não esgota a diversidade de perspectivas sobre o tema. Ela busca, tão somente, ilustrar o caráter persuasivo que costuma impregnar a apresentação e difusão do conceito de "liberdade" em discursos políticos, já que, para além da elucidação de um sentido, sua elaboração conceitual se vincula a princípios capazes de inspirar ações e transformar práticas. Assim, a busca pela elucidação das divergências implica uma avaliação dupla, que considere tanto as delimitações teóricas quanto as práticas historicamente associadas a cada uma das perspectivas em disputa.

\section{A educação libertadora das pedagogias da autonomia}

Se nos voltarmos, novamente, para os discursos educacionais que proclamam como objetivo a vinculação entre educação e "liberdade", a necessidade dessa dupla avaliação fica patente. Grosso modo - e para nossos propósitos - poderíamos classificar tais discursos em duas grandes tendências que, embora não necessariamente derivadas das concepções de "liberdade" acima apresentadas, com elas se relacionam de forma bastante direta.

A primeira delas é formada por uma ampla variedade de correntes pedagógicas e teorias educacionais que gozam de grande prestígio entre educadores brasileiros e nas quais a ideia de uma "educação libertadora" parece se apoiar, de maneira mais ou menos intensa, no exercício da autonomia individual do educando. Aproximam-se, assim, mais claramente, da noção negativa e moderna de liberdade. Nelas o compromisso da educação com a "liberdade" realiza-se na medida em que as práticas pedagógicas evitem interferências exteriores ao sujeito, alheias à sua cultura ou mesmo inadequadas às supostas características de sua faixa etária. Daí, por exemplo, a frequente a substituição do termo "professor" por "mediador", "facilitador da aprendizagem"; signos da recusa à noção de "ensino" em favor de uma alegada "apren- 
dizagem não diretiva" e da valorização de uma suposta "cultura infantil". Num exemplo tão simples quanto frisante da transposição para o campo pedagógico de uma noção de "liberdade negativa”, Neil (1978), um dos grandes expoentes dessa tendência pedagógica, afırma:

A liberdade, numa escola, é simplesmente fazer o que se gosta de fazer, desde que não estrague a paz dos outros, e na prática isso funciona maravilhosamente bem. É relativamente fácil ter essa espécie de liberdade, em especial quando ela é acompanhada de autogoverno por toda comunidade, e se é livre de qualquer tentativa adulta para guiar, sugerir, deitar regras, quando se é livre de qualquer medo dos adultos. (p. 160)

Tratar a afirmação e a promoção da autodeterminação e do autogoverno dos destinatários da educação como signos de "liberdade" parece ser o denominador comum entre as diversas perspectivas educacionais que Barbosa (2008) agrupa sob a denominação de "pedagogias da autonomia”. Nelas poderíamos incluir pensadores tão distintos quanto Dewey e Piaget, Freire e A. Teixeira, cujas obras, a partir de diferentes fundamentos e interesses teóricos, ressaltam a importância de que os processos educacionais e procedimentos pedagógicos considerem o "objeto" da ação educativa como um "sujeito"; alguém apto a intervir ativamente na configuração de seu conhecimento e de seu destino pessoal.

Daí a insistência, igualmente comum, de que as práticas escolares sejam organizadas de forma a minimizar a interferência exterior às crianças e a fomentar sua livre escolha. Nessa perspectiva, o elo entre educação e "liberdade" manifesta-se por meio do cultivo de vivências escolares nas quais os alunos são alegadamente concebidos como protagonistas do ato educativo: assembleias que determinam as regras de convivência, a escolha de percursos formativos a partir de seus interesses e outras medidas análogas, que visariam reduzir ou eliminar o caráter rígido de um processo de escolarização fundado em modelos centrados no "mundo adulto" ou em um "currículo tradicional" e fomentar a autonomia individual.

Em que pese a ampla adesão retórica a esta forma de se conceber os vínculos entre a formação escolar e o cultivo da liberdade, algumas de suas consequências no campo das práticas pedagógicas têm sido objeto de críticas não desprezíveis. Dentre elas a de que, fundadas na noção de infância característica de segmentos econômica e culturalmente privilegiados, as "pedagogias da autonomia” acabam por inspirar modelos que tendem a valorizar atitudes típicas de crianças oriundas desse ethos social - fundado na centralidade da criança no ambiente familiar - em detrimento de experiências de socialização diferentes e mais comuns entre as crianças de classes populares. De forma análoga, o caráter relativamente secundário nelas atribuído aos conhecimentos escolares até então tidos como "clássicos" parece oferecer menos problemas à formação das crianças cujos pais têm alto grau de escolaridade do que àquelas que praticamente representam a primeira geração familiar com acesso à cultura letrada.

Por outro lado, uma crítica menos frequente, mas mais relevante para a análise aqui empreendida, é o fato de que, nas "pedagogias da autonomia", a noção de "liberdade" perde sua conotação de fenômeno tangível e público, de natureza política, para transformar-se em traço de personalidade capaz de ser fomentado a partir de vivências pedagogicamente organizadas. Nessa perspectiva, portanto, o ideal de uma formação educacional comprometida com a liberdade parece estar associado a estratégias pedagógicas para o desenvolvimento de capacidades ou competências individuais, em geral de natureza psicológica e cognitiva. Daí sua identificação tão recorrente com a vaga retórica da formação de um aluno "crítico" ou "reflexivo", supostamente resultante das vivências pedagógicas orientadas para esse fim.

É interessante ainda notar que a vinculação entre educação e liberdade na perspectiva 
de uma pedagogia da autonomia do educando ganhou grande destaque, no caso brasileiro, na vigência do regime autoritário, momento em que a liberdade política desapareceu do espaço comum. Também no caso dos estoicos, a emergência de uma concepção de liberdade ligada à "vida interior" e à alma humana é precedida pela dissolução da democracia e da autonomia da polis. Em ambos os casos, portanto, a liberdade passa a ser concebida como "autonomia da vontade”, ligada ao indivíduo, ao mesmo tempo em que se assiste ao enfraquecimento - ou desaparecimento - da liberdade como desígnio da ação política.

Talvez pudéssemos arriscar, a título de hipótese, que a presente revalorização do ideário das "pedagogias da autonomia", tampouco deva ser dissociada do processo contemporâneo de desqualificação da política. Já não mais se trata do embate com forças tirânicas ou totalitárias, mas antes do enfraquecimento da política em face da naturalização da administração da sociedade, como se esta se reduzisse a um grande organismo econômico e produtivo. Daí a compatibilidade e a coincidência entre os discursos que pregam a autonomia pessoal, a responsabilização individual e o compromisso da educação com o desenvolvimento, no indivíduo, de "competências" supostamente "necessárias" para um "futuro mercado de trabalho" ${ }^{3}$ Imprime-se, assim, ao que sempre foi considerado como o centro de disputas e deliberações de políticas educacionais - currículo, objetivos, avaliação -, o caráter de um curso necessário, imposto ao presente por supostas demandas do desenvolvimento tecnológico e do progresso econômico. Como destaca Franklin L. e Silva (2001):

\section{É nessa naturalização que se oculta a política} de despolitização, isto é, a hegemonia da tecnoburocracia, uma estratégia política que usa a máscara da objetividade técnica para esconder aquilo que se sabe desde a polis grega: que a política é fruto de deliberação humana e não de causas naturais. [...] A obsessão de antecipar tecnicamente o futu $\neg$ ro na gestão tecnocrática do social, como se a sociedade fosse uma grande corporação que se insere no futuro por via de uma planifica $\neg$ ção eficaz, manifesta o propósito de desvalorizar o presente e suas tensões como o lugar em que os homens deveriam deliberar sobre o futuro, atuando politicamente no sentido mais profundo e originá $\neg$ rio do termo, isto é, compartilhando a palavra, e fazendo da palavra política a expressão da responsabilidade inerente à ação histórica. (p. 249)

Assim, em que pese a efetiva contribuição que as pedagogias da autonomia deram ao debate educacional no que concerne à importância da consideração das diferenças culturais e individuais dos educandos e ao seu caráter de "sujeito" no processo educativo, parte significativa dessa modalidade de discurso se apoia no ideal de liberdade como atributo da vontade e da consciência individual, e não como razão de ser da vida política. Ao, eventualmente, evocarem o caráter político da liberdade, as pedagogias da autonomia o fazem como se este fosse resultante da somatória de vontades livres individuais, como se a liberdade enquanto fenômeno político resultasse da mera reunião de "indivíduos livres e autônomos", frutos da exposição a procedimentos pedagogicamente planejados para esse fim. Daí seu frequente recurso à criação de um simulacro pedagógico de república, como se a vida escolar pudesse reproduzir e ensinar aspectos de uma forma de vida cujo vigor parece se esvair na esfera pública contemporânea.

\section{Liberdade e educação como responsabilidade política pelo curso do mundo}

Numa perspectiva bastante crítica às concepções veiculadas pelas "pedagogias da autonomia”, autores como Arendt e Azanha sustentam que o vínculo entre formação educacional e

3. Veja-se, a título de exemplo, os relatórios de educação da OECD. Disponíveis em: <http://www.oecd.org/dataoecd>. 
"liberdade" reside menos no tipo de relação pedagógica que se trava no interior da escola do que na natureza do compromisso desta com o mundo público e com a ação política. Para Arendt (1978), que tomaremos como paradigma dessa vertente, é deletéria a tentativa de transformação da escola num simulacro de vida pública, uma vez que ela não é de modo algum o mundo, nem deve fingir sê-lo. A complexidade do mundo público, os conflitos que o marcam, não são reprodutíveis no âmbito escolar; e se o fossem em sua plenitude, não haveria sentido para a escola, já que ela é precisamente "a instituição que interpomos entre o domínio privado do lar e o mundo com o fito de fazer com que seja possível a transição da família para o mundo" (p. 238). É nesse preciso sentido que Arendt, numa definição que suscita polêmica, classifica as relações pedagógicas como pré-politicas.

Isso não implica sua adesão a uma ideia ingênua de que a escola estaria acima das disputas políticas, por exemplo, no que concerne às suas decisões sobre temas de interesse público, como a extensão do direito de acesso ao ensino, as escolhas curriculares e até mesmo os objetivos expressos no projeto pedagógico de uma unidade escolar. Ela visa simplesmente distinguir a natureza das relações que se estabelecem entre cidadãos na esfera pública das que regulam as interações entre professores e alunos no ambiente escolar. Transpor, de forma imediata e acrítica, os princípios que regem um âmbito para o outro pode ser, no mínimo, temerário.

0 princípio da igualdade, por exemplo, é fundamento da noção de cidadania tanto na tradição clássica como no pensamento político moderno, em que pesem as diferenças entre o que se concebe como igualdade em cada caso ${ }^{4}$. Ora, a relação pedagógica supõe como princípio uma diferença que se traduz numa hierarquia institucional, ainda que necessariamente temporária. Essa diferença hierarquizada não deriva fundamental ou exclusivamente de uma suposta posse de certos conhecimentos especializados por parte do professor, ainda que este aspecto tenha um peso na complexidade dessa relação. Seu funda- mento último repousa, antes, na responsabilidade que os educadores assumem pela apresentação, conservação e busca de um compromisso com a renovação de um mundo comum $^{5}$, do qual são representantes institucionais em face de seus alunos, seres novos nesse mundo.

Isso porque, do ponto de vista político, uma relação entre adultos e crianças é uma relação entre os que são "novos" no mundo e aqueles que nele já habitam, que o constituem política e historicamente e por ele respondem. Daí a incontornável responsabilidade do educador pelo legado histórico-cultural no qual é seu dever iniciar os jovens para que estes possam, futuramente, assumir a dupla e paradoxal responsabilidade de conservá-lo e renová-lo. É desse compromisso político e educacional que deriva a forte convicção de Arendt (1978) de que "qualquer pessoa que se recuse a assumir a responsabilidade coletiva pelo mundo não deveria ter crianças, e é preciso proibi-la de tomar parte em sua educação" (p. 239).

Nessa perspectiva, compete aos educadores iniciar os novos numa herança de artefatos, crenças, instituições, linguagens que constituem nosso mundo comum, cuja durabilidade transcende a vida individual de cada um, tanto no passado como no futuro, e que compartilhamos "não só com aqueles que vivem conosco, mas também com aqueles que aqui estiveram antes e virão depois de nós" (Arendt, 1995, p. 65). Assim, a educação é a forma pela qual cada um de nós vem a deitar raízes nesse mundo ao qual chegamos como estrangeiros, mas com o qual podemos desenvolver laços de pertença e compromissos de renovação de forma a transformá-lo em nosso mundo.

Ora, é essa espécie de vínculo com o mundo que empresta a cada breve existência indivi-

4. Basta, nesse sentido, ressaltar que, para os antigos, a igualdade era concebida fundamentalmente como 0 igual direito à participação política decorrente da isonomiae da isegoria entre os cidadãos - e não tinha conexão imediata, por exemplo, com a justiça social.

5. 0 termo "mundo", em Arendt, não se confunde com o planeta Terra nem com as condições vitais em que a espécie humana se desenvolveu. Refere-se ao artifício humano, aos artefatos fabricados pelos homens, cuja durabilidade fornece um "lar imortal para os mortais". 
dual um lastro de profundidade histórica. Por isso a educação é concebida por Arendt (1978) como “o ponto em que decidimos se amamos o mundo o bastante para assumirmos a responsabilidade por ele e, com tal gesto, salvá-lo da ruína que seria inevitável não fosse a renovação e a vinda dos novos e dos jovens" (p. 247). Mas é também esse vínculo que faculta aos que são novos no mundo - as crianças - a oportunidade de "empreender alguma coisa nova e imprevista para nós" (p. 247), ou seja, que viabiliza a experiência da liberdade como ação no mundo.

Assim, se há, na visão de Arendt, um vínculo entre educação e liberdade, este não se traduz na proposição de práticas pedagógicas que fomentem a decisão e a escolha pessoal, mas numa perspectiva de formação ético-política. Ele toma a forma de um compromisso, a um só tempo, com o mundo que nos é legado e com as crianças que nele chegam e que dele farão o seu mundo. Para Arendt (1990), os homens não nascem livres, mas nascem para a liberdade, que em sua dimensão de conquista política só pode ser experimentada "no espaço das ações livres e das palavras vivas dos homens" (p. 224), ou seja, na experiência compartilhada dos que são dotados da responsabilidade política pelo curso do mundo.

É nessa precisa acepção de um compromisso para com o mundo que, creio, se pode falar de um sentido político da educação em Arendt. Sua insistência em distinguir esses dois âmbitos de atividades - o da educação e o da política - não deve ser compreendida, portanto, como o estabelecimento de uma independência de um em relação ao outro, mas simplesmente como uma distinção relacional. Esta, como destaca Duarte (2009), visa intensificar os limites diferenciais que, como um traço, unem ao mesmo tempo em que separam; estabelecem um tipo de relação em que, na medida em que um polo aumenta (o da igualdade, por exemplo), diminui o outro (o da autoridade). Ora, é somente se, pelo menos em termos conceituais, pudermos manter a distinção, que uma atividade não se confunde com a outra, tornando possível a relação; inviável no caso da fusão.
Assim, é exatamente em benefício do novo - do que é por natureza o imprevisível e o espontâneo; o inesperável no curso das relações entre os homens - que não se pode transformar a ação educativa na fabricação de um amanhã utópico preconcebido por uma geração para ser realizado por outra. Ao assim fazermos, negamos às novas gerações "seu próprio papel futuro no organismo político, pois do ponto de vista dos mais novos, o que quer que o mundo adulto possa propor de novo é necessariamente mais velho do que eles mesmos" (Arendt, 1978, p. 226).

Essa perspectiva que vincula formação educacional e liberdade à vida pública, embora pouco presente no ideário pedagógico contemporâneo, tem uma longa história no pensamento político e educacional do qual este ideário, em alguma medida, se crê herdeiro. Em A Política (455), Aristóteles critica a educação ateniense de seu tempo e louva a dos lacedemônios por seus vínculos com os interesses públicos e não com as necessidades e interesses privados:

Como há um fim único para a cidade toda [o bem comum], é óbvio que a educação deve ser uma só e a mesma para todos, e que sua supervisão deve ser um encargo público e não privado à maneira de hoje (atualmente, cada homem supervisiona a educação de seus próprios filhos, ensinando-lhes em caráter privado qualquer ramo especial de conhecimento que lhe pareça conveniente). Ora, o que é comum a todos deve ser aprendido em comum. [...] É claro, portanto, que tem de haver uma legislação pertinente à educação e que ela deve ser um encargo público. (1997, p. 267)

Assim, também em Aristóteles, a formação de homens livres (1337b) deve resultar de uma educação comprometida com os princípios que regem o âmbito público da existência humana. Por isso ela se volta prioritariamente para o que temos em comum - koinon -, e não para interesses próprios ou conveniências particulares - idion -, que concernem à dimensão privada de nossa existência. Ora, o que os homens têm 
em comum é a própria polis: o espaço em que se movem e as histórias que compartilham, as instituições que os unem em suas singularidades e a possibilidade de deliberarem e responderem por seu destino. É, pois, nela que os homens afirmam, por seus atos e palavras, a liberdade como desígnio de uma existência política. É o pertencimento e a integração a essa modalidade de existência - o biós politikos - que justificam uma formação (Paidéia) para homens livres.

Um ideal formativo dessa magnitude exige, evidentemente, esforços intensos e diversos para sua realização. Não convém, pois, crer que ele venha a resultar da simples renovação e liberalização de procedimentos didático-metodológicos, nem mesmo florescer como consequência imediata de um novo tipo de relação pessoal entre professores e alunos, como parecem sugerir as pedagogias da autonomia. Não que esses aspectos sejam, em si, negligenciáveis. No caso da formação educacional, como na política para Arendt, a escolha dos meios não é uma questão de mera eficácia técnica, uma vez que a forma pela qual se ensina e se aprende é, em si, formativa. No entanto, essas escolhas, bem como a dos aspectos específicos do legado cultural em que deverão ser iniciados os jovens e as crianças, não são "problemas pedagógicos"; são problemas políticos de primeira grandeza. Seu equacionamento exige a assunção da responsabilidade política pela conservação e renovação desse mundo comum. Por se tratar de uma herança comum e pública de linguagens, conhecimentos, valores, objetos materiais e simbólicos, ela não pode ser tratada como amarra que tolhe a autonomia dos novos. Ao contrário, seu cultivo é a condição da existência da liberdade como fenômeno público. E a tarefa da educação com que ela se compromete.

\section{Referências bibliográficas}

ARENDT, H. Entre o passado e o futuro. São Paulo: Perspectiva, 1978.

A condição humana. Rio de Janeiro: Forense Universitária, 1995.

. Da revolução. São Paulo: Ática, 1990.

ARISTOTELES. Política. Brasília: UnB, 1997.

AZANHA, J. M. P. Educação: alguns escritos. São Paulo: Cia. Ed. Nacional, 1987.

BARBOSA, M. Do sonho ao pesadelo: a pedagogia da autonomia sob suspeita. Rev. Bras. Est. Pedagógicos, Brasília, v. 89, n. 223, p. 455-466, set./dez. 2008.

BERLIN, I. Dois conceitos de liberdade. In: HARDY, H.; HAUSHEER, R. (Orgs.). Isaiah Berlin: estudos sobre a humanidade. São Paulo: Companhia das Letras, 2002.

CARVALHO, J. S. Podem a ética e a cidadania ser ensinadas? In: Petrópolis: Vozes, 2004. p. 85-105. (Org.). Educação, cidadania e direitos humanos. Democratização do ensino revisitado. Educação e Pesquisa, São Paulo, v. 30, n. 2, p. 327-334, mai./ago. 2004.

CONSTANT, B. Da liberdade dos antigos comparada à dos modernos. In: MORAES, J. Q. Filosofia política 2. Porto Alegre: LP\&M, 1985.

DUARTE, A. Poder e violência no pensamento político de Hannah Arendt. uma reconsideração. Posfácio à obra "Sobre a violência". Rio de Janeiro: Civilização Brasileira, 2009.

NEILL, A. S. Liberdade, escola, amor e juventude. São Paulo: Ibrasa, 1978.

PASSMORE, J. The philosophy of teaching. Londres: Duckworth, 1984. 
SCHEFFLER, I. A linguagem da Educação. São Paulo: Edusp/Saraiva, 1968.

SILVA, F. 0 mundo vazio: sobre a ausência da política no contexto contemporâneo. In: SILVA, D. A.; MARRACH, S. A. (Orgs.). Maurício Tratemberg: uma vida para as ciências humanas. São Paulo: Unesp, 2001. p.106-118.

Recebido em 18.01.10

Aprovado em 22.06.10

José Sérgio F. de Carvalho cursou graduação em Filosofia e Pedagogia na Universidade de São Paulo. É mestre e doutor em Filosofia da Educação pela Universidade de São Paulo, onde leciona em programas de graduação e pós-graduação. Desenvolve projeto, financiado pelo CNPq, sobre Hannah Arendt, modernidade e educação 